\title{
OPEN The environmental and ecological determinants of elevated Ross River Virus exposure in koalas residing in urban coastal landscapes
}

\author{
Brian J. Johnson ${ }^{1,4}$, Amy Robbins ${ }^{2,4}$, Narayan Gyawali ${ }^{1}$, Oselyne Ong ${ }^{1}$, Joanne Loader ${ }^{2}$, \\ Amanda K. Murphy ${ }^{1,3}$, Jon Hanger ${ }^{2}$ \& Gregor J. Devine ${ }^{1}$
}

Koala populations in many areas of Australia have declined sharply in response to habitat loss, disease and the effects of climate change. Koalas may face further morbidity from endemic mosquito-borne viruses, but the impact of such viruses is currently unknown. Few seroprevalence studies in the wild exist and little is known of the determinants of exposure. Here, we exploited a large, spatially and temporally explicit koala survey to define the intensity of Ross River Virus (RRV) exposure in koalas residing in urban coastal environments in southeast Queensland, Australia. We demonstrate that RRV exposure in koalas is much higher ( $>80 \%)$ than reported in other sero-surveys and that exposure is uniform across the urban coastal landscape. Uniformity in exposure is related to the presence of the major RRV mosquito vector, Culex annulirostris, and similarities in animal movement, tree use, and age-dependent increases in exposure risk. Elevated exposure ultimately appears to result from the confinement of remaining coastal koala habitat to the edges of permanent wetlands unsuitable for urban development and which produce large numbers of competent mosquito vectors. The results further illustrate that koalas and other RRV-susceptible vertebrates may serve as useful sentinels of human urban exposure in endemic areas.

The koala (Phascolarctos cinereus) is an important emblem of Australia's biodiversity and a globally-recognised Australian icon, yet many populations continue to decline ${ }^{1}$. This decline is largely attributable to wide-scale habitat loss, much of it unregulated. During the period from 2000 to 2017, over 7.7 million ha of Australia's wildlife habitat was cleared with less than $10 \%$ being subject to scrutiny under the Environment Protection and Biodiversity Conservation $\mathrm{Act}^{2}$. Of the land lost, ca. 1 million ha was known or potential koala habitat. Such significant habitat losses and associated population declines have resulted in the koala being listed as vulnerable or extinct in much of its historic range ${ }^{3}$. There are pockets where the koala is thriving, but these areas represent a fraction of its native range $\mathrm{e}^{4,5}$. In the state of Queensland, the koala is currently listed as vulnerable in response to ongoing habitat loss and the threats of climate change ${ }^{1,6,7}$. The historical clearing of primary eucalypt forest habitat and accelerated coastal development in the southeast of the state has been associated with particularly sharp population declines ${ }^{8-10}$.

Habitat loss and climate change are not the only threats to the survival of the koala. Infectious disease has also contributed to its decline. The bacterium Chlamydia pecorum causes debilitating ocular and urogenital tract disease while the koala retrovirus (KoRV) has been implicated in host immunosuppression and exacerbation of chlamydial pathogenesis ${ }^{11-14}$. Koalas are also known to be infected by endemic mosquito-borne viruses such Barmah Forest virus (BFV) and Ross River virus (RRV) ${ }^{15,16}$, yet the threat of these viruses to koala health remains poorly studied. RRV is Australia's most medically important mosquito-borne virus that causes debilitating polyarthritis in humans, among other symptoms ${ }^{17}$. The pathology of RRV in marsupial hosts is currently unknown although myositis and arthritis are reported in mice ${ }^{18}$ and domestic horses ${ }^{19}$. Primary vertebrate hosts

\footnotetext{
${ }^{1}$ Mosquito Control Laboratory, OIMR Berghofer Medical Research Institute, Brisbane, OLD 4006, Australia. ${ }^{2}$ Endeavour Veterinary Ecology Pty Ltd, 1695 Pumicestone Rd, Toorbul, QLD 4510, Australia. ${ }^{3}$ School of Public Health and Social Work, Queensland University of Technology, Kelvin Grove, QLD 4059, Australia. ${ }^{4}$ These authors contributed equally: Brian J. Johnson and Amy Robbins. ${ }^{\varpi}$ email: brian.johnson@qimrberghofer.edu.au
} 


\begin{tabular}{|c|c|c|c|}
\hline & Major water class & Minor water class & Other water classes \\
\hline Estuarine & $\begin{array}{l}\text { Tidally influenced estuarine: characterised by man- } \\
\text { groves and related tree communities }\end{array}$ & $\begin{array}{l}\text { Freshwater palustrine: coastal/ sub-coastal: floodplain } \\
\text { tree swamps (melaleuca and eucalypt) }\end{array}$ & $\begin{array}{l}\text { Freshwater lacustrine: artificial/ highly modified wet- } \\
\text { lands (dams, ring tanks, irrigation channel) }\end{array}$ \\
\hline Lacustrine & $\begin{array}{l}\text { Freshwater lacustrine: artificial/ highly modified } \\
\text { wetlands (dams, ring tanks, irrigation channel) }\end{array}$ & $\begin{array}{l}\text { Tidally influenced estuarine: characterised by man- } \\
\text { groves and related tree communities }\end{array}$ & $\begin{array}{l}\text { Freshwater palustrine: coastal/ sub-coastal: floodplain } \\
\text { tree swamps (melaleuca and eucalypt) }\end{array}$ \\
\hline
\end{tabular}

Table 1. Summary of major and minor water body classes present in each surveyed environment.

\begin{tabular}{|c|c|c|c|c|c|c|c|c|c|}
\hline Location & Sample & RRV positive ${ }^{a}$ & RRV negative & $\%$ positive & Odds-ratios & $2.5 \% \mathrm{CI}$ & $97.5 \% \mathrm{CI}$ & z-value & $p$-value \\
\hline \multirow{3}{*}{ Estuarine } & Overall & 73 & 16 & 82.02 & 0.82 & 0.39 & 1.82 & 0.49 & 0.62 \\
\hline & Female & 41 & 9 & 82.00 & 0.99 & 0.36 & 2.98 & 0.01 & 0.99 \\
\hline & Male & 32 & 7 & 82.05 & 1.01 & 0.34 & 2.76 & 0.01 & 0.99 \\
\hline \multirow{3}{*}{ Lacustrine } & Overall & 83 & 15 & 84.69 & 1.21 & 0.55 & 2.57 & 0.49 & 0.62 \\
\hline & Female & 54 & 9 & 85.71 & 1.24 & 0.38 & 3.88 & 0.38 & 0.71 \\
\hline & Male & 29 & 6 & 82.86 & 0.81 & 0.26 & 2.61 & 0.38 & 0.71 \\
\hline
\end{tabular}

Table 2. Seroprevalence of Ross River virus (RRV) in koalas residing in urban coastal lacustrine and estuarine environments. Comparison of seroprevalence rates between environments was performed using data only for animals for which their location could be confirmed $(n=187)$ after accounting for relocated individuals and animals with too few position locations $(n<5)$ to confirm their assignment to a particular environment. ${ }^{a}$ An animal sampled multiple times was considered seropositive if the animal returned a positive test result during any individual sampling event.

are often assumed to be native macropods (e.g. wallabies and kangaroos), but there is considerable debate as to which animals are the primary hosts in urban landscapes where macropods are uncommon but where spillover to humans is often pronounced ${ }^{20,21}$. Although koalas can be locally abundant in the urban landscape as long as suitable green space exists, their relative scarcity and irregular distribution in that environment makes them an unlikely amplifying host for RRV. Remnant urban green spaces are also often resource-poor and therefore may compromise the immunological fitness of koalas living in such spaces ${ }^{22,23}$. Consequently, where RRV exposure is common in urban landscapes, koalas may incur substantial morbidity. Although surveys of captive koalas in New South Wales, Australia, did not find RRV antibodies $(n=12)^{24}$, surveys performed in southern Victoria, Australia, detected RRV antibodies in $16 \%$ of wild koalas $(n=93)^{15,16}$. This latter observation suggests RRV exposure in koalas may present a health risk, but the literature is sparse and exposure among wild koala populations remains largely unknown.

Here, we performed a large, spatially and temporally explicit RRV seroprevalence survey of koalas residing in the urban coastal landscape using sera collected as part of a broader population health survey performed in response to regional infrastructure development. Our purpose was to examine patterns of RRV exposure in coastal koala populations and identify potential correlates of risk related to koala movement and habitat use. Surveys were focused in urban coastal estuarine and lacustrine environments proximate to human developments. These environments are thought to be important sources of RRV spill over to humans ${ }^{25,26}$. Characterising the prevalence of RRV exposure in koalas in these environments might inform a better understanding of RRV transmission from both a public health and a wildlife conservation perspective (Table 1).

\section{Results}

RRV seroprevalence. More than $80 \%$ of koalas tested in the lacustrine and estuarine habitats surveyed had anti-RRV antibodies. Out of 218 koalas tested, 172 koalas were seropositive, 35 were seronegative, and 11 seroconverted from negative to positive over the course of the study (2015 to 2017). The low number of seroconversions during the study reflects the high prevalence of RRV exposure in each population prior to the beginning of the survey. Seroprevalence rates in female and male koalas were similar $\left(84 \%, \mathrm{n}=95 \mathrm{vs} .82 \%, \mathrm{n}=61 ; \chi^{2}=0.07\right.$, $p=0.80$ ) and not influenced by environment (Table 2). This latter analysis contained data from 187 koalas after accounting for relocated individuals and animals with too few position locations $(n<5)$ to confirm their assignment to a particular environment. Overall seroprevalence in the estuarine and lacustrine populations surveyed was $82 \%(n=73)$ and $85 \%(n=83)$, respectively. Multivariate logistic regression analyses further revealed that seroprevalence increased with increasing koala age (Table 3), and that these increases were independent of koala sex (male vs female, $\mathrm{OR}=1.1,95 \% \mathrm{CI} 0.5-2.7, p=0.83$ ) and the environment in which they resided (lacustrine vs estuarine, $\mathrm{OR}=1.0,95 \% \mathrm{CI} 0.43-2.4, p=0.98)$. Koalas aged between $2-4$ years, $4-6$ years, and $>6$ years of age were 6.9 (95\% CI 2.5-22.2, $p<0.001), 8.2$ (95\% 2.6-37.2, $p=0.001)$, and $23.7(4.5-439.9, p=0.003)$ times more likely to test RRV positive, respectively, relative to the baseline age group (<2 years of age) (Fig. 1).

Koala tracking and home range comparisons. Home ranges were calculated for a total of 155 koalas across the lacustrine ( 54 females and 37 males) and estuarine ( 36 females and 28 males) environments after accounting for translocated koalas, those with inadequate sampling duration and those whose home ranges 


\begin{tabular}{|c|c|c|c|c|c|c|}
\hline Variable & Seropositive (\%) & Seronegative (\%) & Seroconverted (\%) & Odds ratio (OR) & OR 95\% CI & $P$-value \\
\hline \multicolumn{7}{|l|}{ Age } \\
\hline$<2$ & $31(56.4 \%)$ & $22(38.6 \%)$ & $2(3.5 \%)$ & Baseline & - & - \\
\hline $2-4$ & $48(85.7 \%)$ & $5(8.5 \%)$ & $3(5.1 \%)$ & 6.9 & $2.5-22.2$ & $<0.001$ \\
\hline $4-6$ & $33(82.5 \%)$ & $3(6.8 \%)$ & $4(9.1 \%)$ & 8.2 & $2.6-37.2$ & 0.001 \\
\hline$>6$ & $33(91.7 \%)$ & $1(2.6 \%)$ & $2(5.3 \%)$ & 23.7 & $4.5-439.9$ & 0.003 \\
\hline
\end{tabular}

Table 3. Summary of seroprevalence results by koala age group and logistic regression outputs for the analysis of the association of koala age with RRV seroprevalence in koalas residing in coastal lacustrine and estuarine environments. Percentages are calculated for the number of individuals in each row. The data shown is only for animals for which their location could be confirmed $(n=187)$ after accounting for relocated individuals and animals with too few position locations $(\mathrm{n}<5)$ to confirm their assignment to a particular environment.

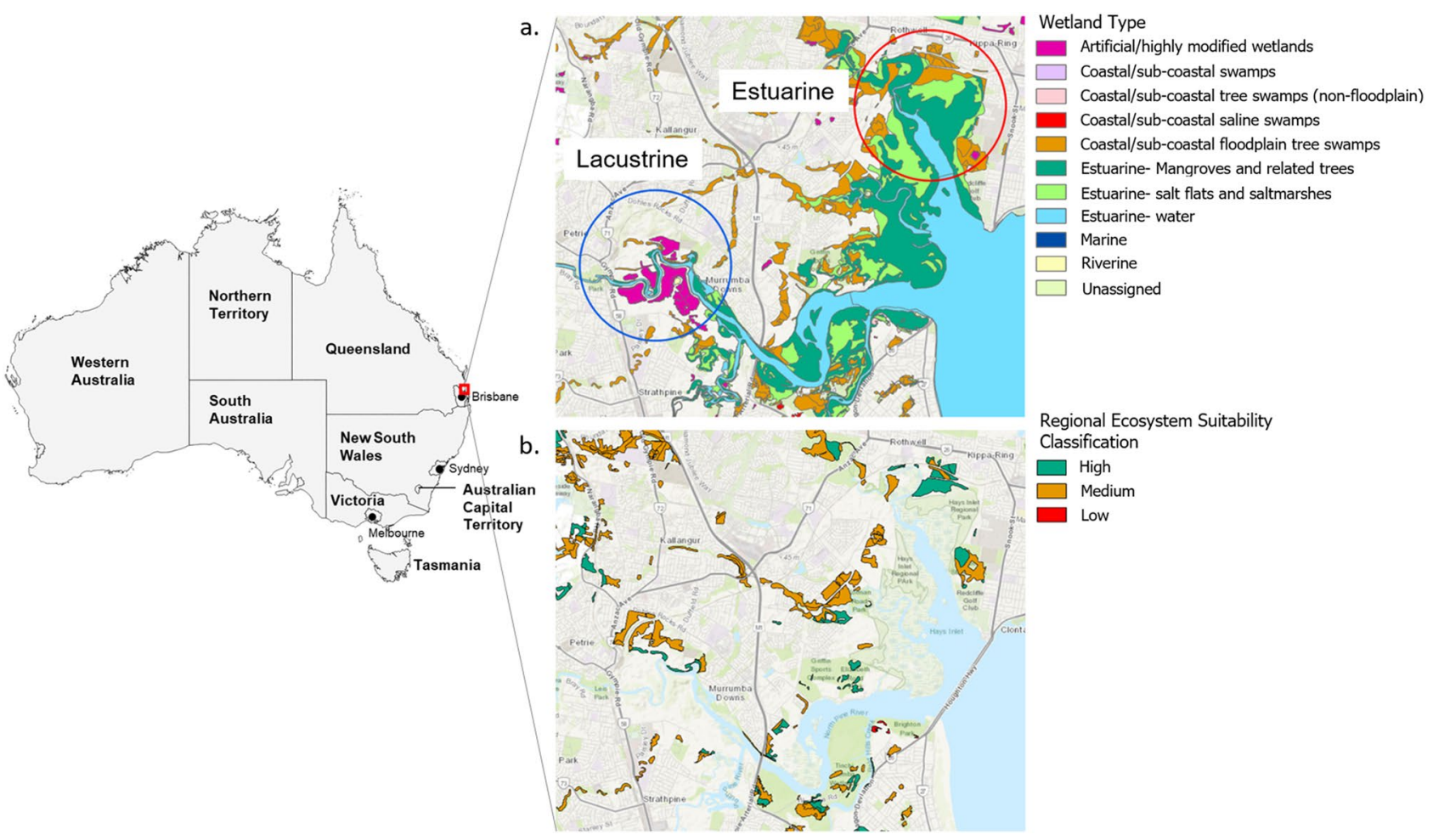

Figure 1. (a) Location of the study area in southeast Queensland, Australia, and summary of primary water bodies present in each surveyed environment. (b) Location and ecosystem suitability classification of koala habitat in the study area as of the most recent state-wide classification (January 2020) ${ }^{7}$. Wetland ${ }^{70}$ and koala habitat $^{71}$ GIS shapefiles were obtained through the QSpatial Catalogue (http://qldspatial.information.qld.gov. $\mathrm{au} /$ ). Base layer of the region area sourced from Esri World Imagery ${ }^{72}$. This figure was created using the ArcGIS Pro software suite (version 2.4.2, https://www.esri.com/en-us/arcgis/products/arcgis-pro).

failed to satisfy the Minimum Convex Polygon (MCP) 60\% cutoff during visual assessment of home range asymptotes. Home ranges did not differ by environment but did differ by sex (Fig. 2a; $F_{1,151}=24.79, p<0.001$ ) with males (mean $=6.1$ ha, 95\% CI 4.9-7.3 ha) having greater home ranges than females (mean $=3.0$ ha, $95 \%$ CI 2.6-3.6 ha). However, no significant differences in home ranges was observed within a sex when considering serostatus (Fig. $2 \mathrm{~b} ; F_{1,151}=1.57, p=0.21$ ). When home ranges were compared between age groups, males and females exhibited a similar trend of increasing home range size with increasing age (Fig. 2c). Significant differences $\left(F_{1,147}=6.28, p=0.01\right)$ between males and females were only observed within the oldest age group, wherein male home ranges (mean $=10.8$ ha, $95 \%$ CI 9.3-12.4 ha) were $26 \%$ larger than those of similarly aged females (mean $=8.0$ ha, 95\% CI 7.0-9.0 ha). Differences between the sexes within the older age group may be attributable to the greater movement of older, dominant males during the mating season ${ }^{27}$. The home ranges of individuals that seroconverted during the study were similar (mean $=6.9$ ha, $95 \%$ CI $3.4-10.4 \mathrm{ha}$ ) to those that were seropositive prior to the study or those that remained seronegative, but too few seroconverted to confidently compare the three groups. 

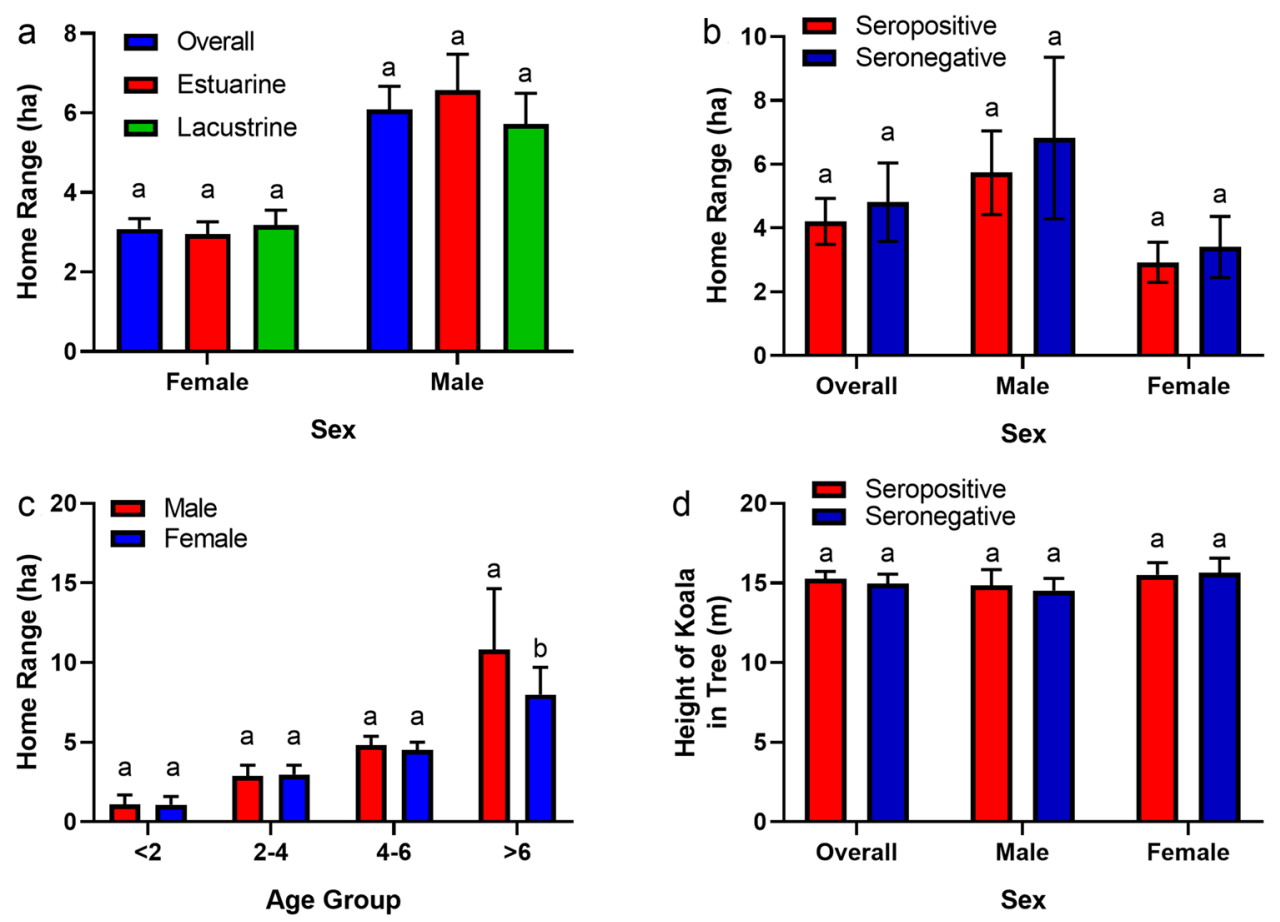

Figure 2. (a) Comparison of annual male and female home ranges (mean $\pm \mathrm{SE}$ ), (b) comparison of annual home ranges (mean \pm SE) of seropositive and seronegative koalas, (c) comparison of male and female home ranges by age group (mean $\pm \mathrm{SE}$ ), and (d) comparison of koala height (mean $\pm \mathrm{SE}$ ) in trees for seropositive and seronegative koalas. Bars within a graph that do not share similar letters denote statistical significance.

Koala tree use by environment. Koalas were found to utilize 38 and 56 individual tree species in the estuarine and lacustrine environments, respectively. Although the overall tree communities were unique in relation to the environment, the dominant species used by koalas in each environment were similar (Table 4). Koalas favoured Eucalyptus tereticornis (blue gum) and E. siderophloia (grey ironbark) in the estuarine environment and E. racemosa (scribbly gum) and E. tereticornis in the lacustrine environment. Other species commonly used by koalas included Corymbia intermedia (pink bloodwood) and Melaleuca quinquenervia (broad-leaved paperbark) in the estuarine environment and Cinnamomum camphora (camphor laurel) and C. intermedia in the lacustrine environment. Tree selection between seropositive and seronegative koalas was similar with nine of the top ten most used tree species being shared between them (Table 5). Both male and female koalas preferred mature trees with greater diameter at breast height (DBH; male 95\% CI 40.94-42.96 cm; female 95\% CI 42.18-44.62 cm) and occupied similar heights in trees (Fig. 2d; male 95\% CI 14.82-15.55 m; female 95\% CI $14.09-15.31 \mathrm{~m})$. No significant $\left(F_{1,305}=0.24, p=0.62\right)$ differences for either variable were observed between environments or by serostatus.

Mosquito community composition. As expected, the estuarine environment contained more of the saltmarsh associated species Aedes vigilax, Culex sitiens and Aedes alternans relative to the lacustrine environment that harbored a greater diversity and abundance of freshwater associated species such as Culex annulirostris and Aedes procax (Table 6). Cx. annulirostris dominated both habitats, accounting for $86 \%$ and $41 \%$ of all collections from the lacustrine and estuarine environments, respectively. While the abundance of mosquitoes in both environments was substantial, the estuarine environment had the greatest number of mosquitoes per surveillance event $(11,199 \pm 2,688$ vs. $5,576 \pm 2,696)$.

\section{Discussion}

The risk of arbovirus transmission to both humans and wildlife is influenced by the environment and is therefore spatially heterogeneous. Distinct patterns of increased human RRV risk in southeast Queensland (SEQ) appear to be driven by environmental changes in vector-vertebrate communities ${ }^{21,28}$, but little is known of the factors driving environmental and spatial risks of RRV transmission to endemic wildlife. In the present study, we demonstrate that RRV seropositivity in koalas can be far greater than that reported for other marsupial species ${ }^{17,29}$ and other circulating arboviruses such as $\mathrm{BFV}^{15,30}$. Uniformity in exposure is related to the presence of the major RRV mosquito vector, Culex annulirostris, and similarities in koala movement, tree use, and age-dependent increases in exposure risk. The findings suggest that elevated RRV exposure in coastal koala populations is related to the confinement of remaining koala habitat to the edges of permanent wetlands that are unsuitable for further development and which produce large numbers of mosquito vectors. The discovery of high RRV prevalence in 


\begin{tabular}{|c|c|c|c|c|c|c|c|c|c|}
\hline \multirow[b]{2}{*}{ Tree species } & \multicolumn{4}{|c|}{ Estuarine } & \multirow[b]{2}{*}{ Tree species } & \multicolumn{4}{|c|}{ Lacustrine } \\
\hline & Count & DBH $(\mathrm{cm})$ & Tree height (m) & Koala height (m) & & Count & DBH $(\mathrm{cm})$ & Tree height (m) & Koala height (m) \\
\hline $\begin{array}{l}\text { Eucalyptus tereticornis } \\
\text { (blue gum) }\end{array}$ & 6446 & 53.62 & 21.07 & 16.61 & $\begin{array}{l}\text { Eucalyptus racemosa } \\
\text { (scribbly gum) }\end{array}$ & 2268 & 66.79 & 22.08 & 18.38 \\
\hline $\begin{array}{l}\text { Eucalyptus siderophloia } \\
\text { (grey ironbark) }\end{array}$ & 3937 & 40.30 & 19.27 & 16.10 & $\begin{array}{l}\text { Eucalyptus tereticornis } \\
\text { (blue gum) }\end{array}$ & 2157 & 62.02 & 21.39 & 16.36 \\
\hline $\begin{array}{l}\text { Melaleuca quinquenervia } \\
\text { (paperbark) }\end{array}$ & 882 & 25.73 & 13.79 & 12.01 & $\begin{array}{l}\text { Cinnamomum camphora } \\
\text { (camphor laurel) }\end{array}$ & 1145 & 45.39 & 15.12 & 12.89 \\
\hline $\begin{array}{l}\text { Corymbia intermedia } \\
\text { (pink bloodwood) }\end{array}$ & 835 & 39.65 & 18.45 & 15.33 & $\begin{array}{l}\text { Eucalyptus grandis } \\
\text { (flooded gum) }\end{array}$ & 953 & 46.02 & 26.25 & 21.71 \\
\hline $\begin{array}{l}\text { Casuarina glauca (she- } \\
\text { oak) }\end{array}$ & 738 & 25.71 & 13.87 & 11.67 & $\begin{array}{l}\text { Corymbia intermedia } \\
\text { (pink bloodwood) }\end{array}$ & 885 & 36.72 & 18.39 & 14.58 \\
\hline $\begin{array}{l}\text { Corymbia tessellaris } \\
\text { (Moreton Bay ash) }\end{array}$ & 226 & 40.99 & 19.59 & 15.26 & $\begin{array}{l}\text { Lophostemon confertus } \\
\text { (brushbox) }\end{array}$ & 586 & 40.16 & 19.22 & 16.89 \\
\hline $\begin{array}{l}\text { Lophostemon confertus } \\
\text { (brushbox) }\end{array}$ & 101 & 39.03 & 19.39 & 16.74 & $\begin{array}{l}\text { Eucalyptus siderophloia } \\
\text { (grey ironbark) }\end{array}$ & 398 & 38.74 & 19.33 & 15.61 \\
\hline Mangrove & 93 & 15.72 & 7.36 & 6.25 & $\begin{array}{l}\text { Melaleuca quinquenervia } \\
\text { (paperbark) }\end{array}$ & 373 & 34.77 & 14.07 & 12.11 \\
\hline $\begin{array}{l}\text { Eucalyptus grandis } \\
\text { (flooded gum) }\end{array}$ & 90 & 80.70 & 21.74 & 16.29 & $\begin{array}{l}\text { Casuarina glauca (she- } \\
\text { oak) }\end{array}$ & 276 & 27.02 & 13.00 & 10.56 \\
\hline $\begin{array}{l}\text { Lophostemon suaveolens } \\
\text { (swampbox) }\end{array}$ & 70 & 25.06 & 11.71 & 9.91 & $\begin{array}{l}\text { Eucalyptus pilularis } \\
\text { (blackbutt) }\end{array}$ & 228 & 77.66 & 29.53 & 24.44 \\
\hline Acacia sp. & 50 & 18.04 & 9.58 & 7.65 & $\begin{array}{l}\text { Lophostemon suaveolens } \\
\text { (swampbox) }\end{array}$ & 181 & 23.75 & 13.57 & 11.10 \\
\hline Eucalyptus sp. & 45 & 52.29 & 17.64 & 14.07 & Pinus elliottii (slash pine) & 174 & 31.88 & 18.93 & 15.90 \\
\hline $\begin{array}{l}\text { Corymbia citriodora } \\
\text { (spotted gum) }\end{array}$ & 33 & 58.79 & 22.00 & 18.88 & Ficus sp. & 170 & 60.20 & 14.49 & 11.94 \\
\hline $\begin{array}{l}\text { Eucalyptus propinqua } \\
\text { (grey gum) }\end{array}$ & 29 & 37.21 & 14.38 & 11.92 & $\begin{array}{l}\text { Eucalyptus propinqua } \\
\text { (grey gum) }\end{array}$ & 143 & 49.21 & 17.61 & 14.98 \\
\hline Dead tree & 12 & 23.08 & 10.92 & 9.42 & Acacia sp. & 134 & 25.82 & 11.55 & 8.45 \\
\hline $\begin{array}{l}\text { Eucalyptus fibrosa } \\
\text { (broad-leaved ironbark) }\end{array}$ & 12 & 40.42 & 20.00 & 17.00 & $\begin{array}{l}\text { Corymbia tessellaris } \\
\text { (Moreton Bay ash) }\end{array}$ & 126 & 36.10 & 18.87 & 16.97 \\
\hline $\begin{array}{l}\text { Eucalyptus robusta } \\
\text { (swamp mahogany) }\end{array}$ & 12 & 41.83 & 14.67 & 12.50 & $\begin{array}{l}\text { Eucalyptus microcorys } \\
\text { (tallowwood) }\end{array}$ & 126 & 51.94 & 20.17 & 15.53 \\
\hline $\begin{array}{l}\text { Eucalyptus microcorys } \\
\text { (tallowwood) }\end{array}$ & 11 & 44.27 & 17.27 & 12.38 & Pinus sp. & 63 & 34.57 & 18.14 & 15.75 \\
\hline Ficus sp. & 9 & 44.89 & 10.11 & 7.33 & Mangrove & 59 & 27.81 & 11.58 & 11.25 \\
\hline
\end{tabular}

Table 4. Dominant tree species and characteristics of trees in which koalas were located during the study. Count represents the total number of observations (animal relocations) during which a koala was observed on an individual tree species. The data presented for tree diameter at breast height (DBH), tree height, and koala height in trees represents the mean data for all koalas surveyed in each environment. The tree species shown represents $>95 \%$ of animal relocations in each environment.

\begin{tabular}{|c|c|c|c|c|c|}
\hline \multicolumn{3}{|l|}{ Seropositive Koalas } & \multicolumn{3}{|l|}{ Seronegative Koalas } \\
\hline Tree species & $\%$ of animal relocations & \# of relocations & Tree species & $\%$ of animal relocations & \# of relocations \\
\hline Eucalyptus tereticornis (blue gum) & 27.51 & 6799 & Eucalyptus tereticornis (blue gum) & 38.61 & 2218 \\
\hline Eucalyptus siderophloia (grey ironbark) & 13.27 & 3279 & Eucalyptus siderophloia (grey ironbark) & 23.32 & 1340 \\
\hline Eucalyptus racemosa (scribbly gum) & 8.66 & 2141 & Corymbia intermedia (pink bloodwood) & 7.42 & 426 \\
\hline Corymbia intermedia (pink bloodwood) & 5.73 & 1417 & Melaleuca quinquenervia (paperbark) & 6.18 & 355 \\
\hline Cinnamomum camphora (camphor laurel) & 4.56 & 1127 & Casuarina glauca (she-oak) & 4.09 & 235 \\
\hline Eucalyptus grandis (flooded gum) & 4.16 & 1028 & Eucalyptus moluccana (gum-topped box) & 2.68 & 154 \\
\hline Melaleuca quinquenervia (paperbark) & 4.05 & 1002 & Eucalyptus racemosa (scribbly gum) & 2.30 & 132 \\
\hline Eucalyptus moluccana (gum-topped box) & 3.69 & 911 & Corymbia citriodora (spotted gum) & 2.11 & 121 \\
\hline Casuarina glauca (she-oak) & 3.38 & 835 & Lophostemon confertus (brushbox) & 2.00 & 115 \\
\hline Lophostemon confertus (brushbox) & 2.64 & 652 & Lophostemon suaveolens (swampbox) & 1.38 & 79 \\
\hline
\end{tabular}

Table 5. Common tree species used by Ross River virus seropositive and seronegative koalas across both study areas. Tree use is represented by the percentage (mean) of animal relocations during which a koala was observed on an individual tree species. 
\begin{tabular}{|l|l|l|l|l|} 
Total collected & Mean & Std. error of mean & $\%$ of total collected (mean) & SE of \% of total
\end{tabular}

\begin{tabular}{|c|c|c|c|c|c|}
\hline \multicolumn{6}{|l|}{ Lacustrine } \\
\hline Aedes alternans & 0 & 0 & 0 & 0 & 0 \\
\hline Aedes aculeatus & 33 & 11 & 8.62 & 0.77 & 0.59 \\
\hline Aedes notoscriptus & 202 & 67.33 & 37.95 & 1.79 & 0.68 \\
\hline Aedes procax & 139 & 139 & 0 & 0.62 & 0.62 \\
\hline Aedes vigilax & 302 & 100.7 & 51.36 & 2.07 & 0.35 \\
\hline Aedes vittiger & 0 & 0 & 0 & 0 & 0 \\
\hline Anopheles annulipes & 512 & 170.7 & 167.7 & 2.64 & 1.63 \\
\hline Culex annulirostris & 13,993 & 4664 & 2219 & 86.25 & 6.34 \\
\hline Culex hilli & 0 & 0 & 0 & 0 & 0 \\
\hline Culex sitiens & 1518 & 506 & 506 & 5.61 & 5.61 \\
\hline Uranotaenia sp. & 29 & 9.667 & 9.17 & 0.25 & 0.13 \\
\hline \multicolumn{6}{|l|}{ Estuarine } \\
\hline Aedes alternans & 1252 & 417.3 & 201.5 & 3.7 & 1.19 \\
\hline Aedes aculeatus & 0 & 0 & 0 & 0 & 0 \\
\hline Aedes notoscriptus & 0 & 0 & 0 & 0 & 0 \\
\hline Aedes procax & 0 & 0 & 0 & 0 & 0 \\
\hline Aedes vigilax & 6755 & 2252 & 1068 & 27.78 & 17.88 \\
\hline Aedes vittiger & 50 & 0 & 0 & 0.13 & 0.13 \\
\hline Anopheles annulipes & 0 & 0 & 0 & 0 & 0 \\
\hline Culex annulirostris & 16,846 & 8423 & 80 & 40.6 & 20.35 \\
\hline Culex hilli & 306 & 153 & 52 & 0.73 & 0.41 \\
\hline Culex sitiens & 8389 & 2796 & 762.9 & 27.07 & 6.51 \\
\hline Uranotaenia sp. & 0 & 0 & 0 & 0 & 0 \\
\hline
\end{tabular}

Table 6. Summary of mosquito species collected in each surveyed environment. Two $\mathrm{CO}_{2}$-baited light traps were set at each sampling site across four $(n=4)$ surveillance events.

these populations supports the need for future investigations into the population health consequences of RRV and other endemic arboviruses in koalas.

Habitat loss and fragmentation disrupts many important ecological processes including population dynamics and resource use $\mathrm{s}^{31-33}$. It is further linked to increases in human disease risk for a variety of zoonotic diseases within urban environments through processes related to population isolation, reductions in host species richness, and increases in the abundance of urban adapted, highly competent host and vector species ${ }^{34-37}$. The current study reveals, for the first time, high RRV seroprevalence in koala populations residing in degraded urban coastal habitats. Resource related reductions in immunological fitness ${ }^{22,23}$, combined with often elevated animal densities in remnant coastal habitat patches ${ }^{7}$, may contribute to elevated RRV and other infectious disease prevalence in the surveyed populations ( $35 \%$ C. pecorum, 100\% KoRV-A and 24\% KoRV-B) ${ }^{38}$. The influence of habitat disturbance on RRV risk to koalas is further supported by lower seroprevalence rates $(13 \% ; n=93)$ in koalas residing in the coastal Gippsland Lakes region of Victoria, Australia ${ }^{15,16}$, a region containing ca. 20,000 ha of protected natural habitat. However, we cannot attribute these differences to quality of habitat alone, as climate variability between regions will have differing impacts on RRV transmission intensity. Of note, although tree use by koalas in this study was similar to that reported elsewhere ${ }^{39-41}$, recent infrastructure developments in the study area have resulted in the loss of ca. 53 ha of koala habitat and the removal of at least 17,000 maturing trees ${ }^{42,43}$. This has clearly degraded the quality of this habitat overall and may influence future patterns of koala tree use and resource-related associations with arbovirus exposure in the areas surveyed.

The risk of disease exposure in wildlife often increases with animal age. Age-related increases in seropositivity has been demonstrated in koalas for $\mathrm{KoRV}^{44}$, as older animals are more likely to become infected due to having more contact with other koalas. The likelihood of vector-host contact also increases with age and reports on humans ${ }^{17}$ and other marsupial species ${ }^{24,29}$ demonstrate that antibody prevalence often increases with increasing age. Our data reflects the same pattern and is supported by the majority of seronegative koalas being $<2$ years of age and the relatively young age of individuals that positively seroconverted during the study. It is difficult to give much weight to the latter finding, however, considering the low number of seroconversions observed. Our results further suggest that exposure is related to age-dependent patterns of movement, as both exposure and movement increased proportionally with increasing koala age. The home ranges observed in this study (males $=6.1 \mathrm{ha}$, females $=3.3 \mathrm{ha}$ ) are similar to those of koalas residing in another urban coastal habitat in Victoria, Australia (males $=9.1$ ha, females $=4.3 \mathrm{ha})^{45}$, and general patterns of movement observed may reflect a combination of age and resource-limited ${ }^{27,45,46}$ effects. Exposure ultimately appears to be dependent upon multiple demographic and habitat related factors, and the interactions between them. Thus, additional studies performed across varied habitats are needed to better understand how such factors influence exposure risk in koalas to RRV and other arboviruses. 
Although several mosquito species captured in each environment are known to transmit RRV, including $C x$. annulirostris, Ae. vigilax and $C x$. sitiens, historical evidence suggests $C x$. annulirostris is the most likely vector for koalas. This mosquito has a tendency to seek hosts above ground level ${ }^{47,48}$, and commonly blood-feeds on marsupials, including tree-dwelling species like the brushtail possum ${ }^{49,50}$. The presence of $C x$. annulirostris may expose koalas to other circulating arboviruses, as it is also a principal vector of BFV, Murray Valley encephalitis and West Nile Kunjin viruses ${ }^{49,51}$. Of these, BFV is the second most medically important endemic mosquitoborne disease in SEQ and serological investigations implicate marsupials as the largest and most diverse group of reservoirs ${ }^{52}$. Although previous reports suggest exposure to BFV in koalas is low ( $9 \%$ seroprevalence $)^{15}$, the limited number of studies justifies additional investigations.

Lastly, infection in vertebrate hosts at the wildlife-human interface may be used to forecast the risk of spillover to the human population ${ }^{53,54}$. Although the spatial distribution of human RRV cases is extensive, there are elevated risks associated with suburban areas harbouring a greater proportion of wetlands and bushland and an increased presence of $C x$. annulirostris and other freshwater mosquitoes ${ }^{25,28,55}$. These observations are corroborated by reports of RRV outbreaks being preceded by above-average rainfall events ${ }^{56,57}$ that provide temporary freshwater larval habitats for $C x$. annulirostris populations for extended periods of time. Increased monitoring of disease exposure in non-human vertebrate populations, such as koalas, may enhance our understanding of the environmental and ecological determinants of human exposure.

\section{Conclusion}

This survey represents one of the largest single-species marsupial seroprevalence surveys performed to date. The scale and scope of the survey provided key insights into the environmental and ecological determinants of RRV exposure in koalas residing in the urban coastal landscape. Substantial risks of exposure are associated with confinement of remnant coastal koala habitat to the edges of permanent wetland features that produce large numbers of competent mosquito vectors. Particular importance is attributed to the presence of freshwater habitat suitable to $C x$. annulirostris mosquitoes. These results demonstrate that the careful study and sampling of wildlife populations can yield insights relevant to animal conservation and public health in rapidly changing urban landscapes.

\section{Methods}

Study area. Koalas were surveyed in coastal estuarine and lacustrine environments (Fig. 1a, Table 1) located in the Moreton Bay Region (MBR) of SEQ $\left(27.2337^{\circ} \mathrm{S}, 153.0683^{\circ} \mathrm{E}\right.$ and $27.2685^{\circ} \mathrm{S}, 152.9896^{\circ} \mathrm{E}$, respectively), Australia. Koala habitat loss and fragmentation due to urban development in the two study areas has been severe over the last decade and remaining koala habitat is largely confined to the edges of swampy and/or flood-prone areas unsuitable for further development (Fig. 1b) ${ }^{43}$. Much of the remaining habitat in the more developed lacustrine study area is heavily fragmented and classified as medium quality, or suitability, for koalas ${ }^{7}$, whereas the less developed estuarine environment contains a greater proportion of high quality habitat. Both surveyed environments harbor mosquito faunas typical of the region's saltwater (Ae. vigilax) and freshwater (Cx. annulirostris) habitats because of their proximity to permanent water features. These species are significant vectors of RRV and readily blood-feed on humans and a variety of non-human vertebrates including marsupials ${ }^{50,58,59}$.

Endemic human circulation of RRV occurs in the region, with an average of 259 human cases/year notified between January 2012 and December 2016 (Data provided by the Queensland Department of Health, Communicable Diseases Branch, QIMRB Human Research Ethics Committee Approval no. P2238; Fig. S1). Human disease cases are reported in the region (and in broader SEQ) year-round, commonly peaking between February and May each year. This coincides with the late austral summer and autumn seasons, when seasonal increases in mosquito abundance occur.

Koala sampling, collaring and aging. We surveyed 223 koalas as part of a regional koala management program undertaken in response to a large, multi-year transport infrastructure development (Moreton Bay Rail Project; see Hanger et al. ${ }^{43}$ ) that spanned both study areas. Koalas were captured using traps or the flag and pole technique and transported to the Endeavour Veterinary Ecology facilities in Toorbul, SEQ. Here, experienced veterinarians conducted a comprehensive clinical examination under anaesthesia to assess koala health which included the collection of a blood sample from the cephalic vein. During this examination, an estimated year of birth was determined for each koala based on the wear of the upper premolar and molar teeth ${ }^{60}$. For joeys, a date of birth was determined based on the developmental characteristics and size of the joey relative to a reference chart of known-age joeys. Initial age estimation enabled us to determine the approximate age of each koala during subsequent serum collection events. Following examination, healthy koalas were fitted with identification and telemetry devices to facilitate monitoring in the field. After recovery from anaesthesia, they were transported back to the study area for release at their point of capture (or as close as practicable based on safety or welfare concerns). Collaring and tracking of koalas began in March 2013 and ceased in January 2017.

Koala tracking. Koala tracking and monitoring followed the methods of Robbins et al. ${ }^{61}$ Briefly, koalas weighing more than $3 \mathrm{~kg}$ were monitored using near-real-time biotelemetry devices (K-Tracker telemetry system, LX Group, Sydney, New South Wales) that reported global positioning system (GPS) locations and activity levels from each tagged koala via 12-hourly data uploads to an internet-based server. Koala position and activity levels were monitored remotely via the internet every $24 \mathrm{~h}$ but koalas were also field-tracked using very high frequency (VHF) radiotelemetry at least once per fortnight. Koalas weighing between 1 and $3 \mathrm{~kg}$ were not large enough to be fitted with the K-Tracker collars, so were field-tracked using VHF radiotelemetry several times a week. Koalas were monitored more frequently if there were health or welfare concerns, or if activity data 
reported by $K$-Tracker collars indicated low or zero activity. At each field monitoring event, koalas were examined with binoculars and various data recorded, including GPS location, tree $\mathrm{DBH}$, tree species, tree height, the koala's height in the tree, external signs of health and the presence or absence of joeys. DBH was measured using a DBH tape and the maximum DBH measurement was recorded for each tree. Tree height and koala height was estimated by experienced field technicians. Koalas included in this study were monitored for a period ranging from 1 to 46 months (mean $=7.98 ; 95 \% \mathrm{CI}=7.54$ to 8.54 months), which enabled determination of movement patterns and resource preferences.

Home range determination. The geo-referenced position data were used to calculate the home range sizes for each individual koala using the adehabitatHR package in $\mathrm{R}^{62}$. Prior to analysis, each position was mapped with QGIS software ${ }^{63}$ to provide a visual indication of home ranges and ensure quality of data. Home range sizes were determined by minimum convex polygon (MCP 95\%) estimation for each year the animal was monitored. Mean home range sizes were determined by averaging home range estimates across all surveyed years for each individual. In select cases, annual home ranges were estimated with lower confidence (cutoff MCP $\geq 60 \%$ ) based on visual inspections of home range asymptote plots.

Serum collection and determination of seroprevalence. Koala sera were collected opportunistically between 2015 and 2017. A total of 529 blood samples were taken from 218 koalas. Some koalas were bled more than once (range $=1-6$ serum samples/koala; mean $=2.3$ ), creating the opportunity to investigate seroconversion in koalas. The presence of neutralising antibodies against RRV in each serum sample was tested in duplicate by preparing a monolayer of mammalian cell lines (Vero) in a 12-well tissue culture plate. Dilutions (1:10) of koala sera in RPMI-1640 (Sigma-Aldrich, USA) and the virus isolate RRV T48 ${ }^{64}$ were introduced to each well, sufficient to produce 50 to 60 plaques in the absence of antibody. Plates were incubated for two hours after which the virus-serum mixture was supplemented with $0.75 \%$ carboxymethylcellulose (CMC, Sigma-Aldrich, USA) overlay medium in ds-RPMI. Plates were incubated at $37^{\circ} \mathrm{C}$ and $5 \% \mathrm{CO}_{2}$ for a further 2 days, fixed with crystal violet and examined for cytopathic effects (CPE), which can be determined by counting the number of plaques. Neutralising antibodies bind to the virus, preventing CPE and the formation of plaques. Koala sera that neutralised $\geq 50 \%$ of plaques in these assays were considered anti-RRV seropositive ${ }^{65}$. This methodology has been deployed in a number of studies ${ }^{66,67}$, and has been tested at dilution rates of $>160$ fold confirming strong and specific binding by the antibody ${ }^{67}$. We considered an animal sampled multiple times as seropositive if the animal returned a positive test result during any individual sampling event.

Mosquito community composition. The mosquito community in each location was characterized from February to March 2020; months associated with high mosquito and RRV activity in the region ${ }^{68}$. Mosquitoes were collected using CDC light traps (Pacific Biologics, Brisbane, Australia) baited with $\mathrm{CO}_{2}$ from dry ice on 4 dates. Two traps were set within each environment either weekly or fortnightly depending on weather. Traps were operated from 18:00 to 06:00 during each surveillance event. Captured mosquitoes were transported back to the laboratory where they were stored at $-20^{\circ} \mathrm{C}$ until identified to species using standard taxonomic keys.

Statistical analysis. Fisher's exact test was used to compare differences in the number of positive sera results obtained in each surveyed environment. Two-way ANOVA was used to compare differences in home range sizes and the mean height of koalas in trees between seropositive and seronegative individuals. We used a generalized linear logistic model with the logit link function to determine the association between sero status and koala age. For this analysis, we grouped koalas into four age groups. Age groups included koalas $<2$ years of age, those between 2 and 4 years of age, those between 4 and 6 years of age, and those $>6$ years of age. Koala sex and location were included as co-variables in the model.

Regulatory approvals. The koala management program was conducted under approvals issued by the Queensland Department of Agriculture and Fisheries (approvals CA 2012/03/597, CA 2013/09/719, CA 2014/06/777, CA 2015/03/852, and CA 2016/03/950). Animal ethics and research work was authorized by scientific purposes permits issued by the Queensland Department of Environment and Heritage Protection (approvals WISP 11525212, WISP 16125415, WISP 13661313, WITK 14173714 and WISP 17273716). All experiments were performed in accordance with the relevant guidelines and regulations. All studies involving animals are reported in accordance with the ARRIVE guidelines for reporting experiments involving animals ${ }^{69}$.

Received: 28 August 2020; Accepted: 9 February 2021

Published online: 24 February 2021

\section{References}

1. Gonzalez-Astudillo, V., Allavena, R., McKinnon, A., Larkin, R. \& Henning, J. Decline causes of Koalas in South East Queensland, Australia: a 17-year retrospective study of mortality and morbidity. Sci. Rep. 7, 42587 (2017).

2. Ward, M. S. et al. Lots of loss with little scrutiny: The attrition of habitat critical for threatened species in Australia. Conserv. Sci. Pract. 1, e117 (2019).

3. Martin, R. \& Handasyde, K. The Koala: Natural History, Conservation and Management (University of New South Wales Press Ltd (Hong Kong, Australian Natural History Series, 1999). 
4. McAlpine, C. et al. Conserving koalas: A review of the contrasting regional trends, outlooks and policy challenges. Biol. Conserv. 192, 226-236 (2015).

5. Shumway, N., Lunney, D., Seabrook, L. \& McAlpine, C. Saving our national icon: An ecological analysis of the 2011 Australian Senate inquiry into status of the koala. Environ. Sci. Policy 54, 297-303 (2015).

6. Adams-Hosking, C., Grantham, H. S., Rhodes, J. R., McAlpine, C. \& Moss, P. T. Modelling climate-change-induced shifts in the distribution of the koala. Wildlife Res. 38, 122-130 (2011).

7. Rhodes, J. R., Beyer, H., Preece, H. \& McAlpine, C. South East Queensland koala population modelling study. UniQuest (2015).

8. Dique, D. S., Preece, H. J., Thompson, J. \& de Villiers, D. L. Determining the distribution and abundance of a regional koala population in south-east Queensland for conservation management. Wildlife Res. 31, 109-117 (2004).

9. Thompson, J. The comparative ecology and population dynamics of koalas in the Koala Coast region of south-east Queensland. $\mathrm{PhD}$ Thesis, School of Integrative Biology, University of Queensland (2006).

10. Rhodes, J. R. et al. Using integrated population modelling to quantify the implications of multiple threatening processes for a rapidly declining population. Biol. Conserv. 144, 1081-1088 (2011).

11. Denner, J. \& Young, P. R. Koala retroviruses: Characterization and impact on the life of koalas. Retrovirology 10, 108 (2013).

12. Nyari, S. et al. Epidemiology of chlamydial infection and disease in a free-ranging koala (Phascolarctos cinereus) population. PloS One 12 (2017).

13. Waugh, C. A. et al. Infection with koala retrovirus subgroup B (KoRV-B), but not KoRV-A, is associated with chlamydial disease in free-ranging koalas (Phascolarctos cinereus). Sci. Rep. 7, 1-11 (2017).

14. McCallum, H., Kerlin, D. H., Ellis, W. \& Carrick, F. Assessing the significance of endemic disease in conservation-koalas, chlamydia, and koala retrovirus as a case study. Conserv. Lett. 11, e12425 (2018).

15. Aldred, J., Campbell, J., Mitchell, G., Davis, G. \& Elliott, J. Involvement of wildlife in the natural cycle of Ross River and Barmah Forest viruses (Wildlife Disease Association Meeting, Melbourne, Australia, 1991).

16. Russell, R. C. Arboviruses and their vectors in Australia: An update on the ecology and epidemiology of some mosquito-borne arboviruses. Rev. Med. Vet. Entomol. 83, 141-158 (1995).

17. Harley, D., Sleigh, A. \& Ritchie, S. Ross River virus transmission, infection, and disease: A cross-disciplinary review. Clin. Microbiol. Rev. 14, 909-932 (2001).

18. Seay, A. R. \& Wolinsky, J. S. Ross river virus-induced demyelination: I Pathogenesis and histopathology. Ann. Neurol. 12, 380-389 (1982).

19. Azuolas, J., Wishart, E., Bibby, S. \& Ainsworth, C. Isolation of Ross River virus from mosquitoes and from horses with signs of musculoskeletal disease. Aust. Vet. J. 81, 344-347 (2003).

20. Stephenson, E. B., Peel, A. J., Reid, S. A., Jansen, C. C. \& McCallum, H. The non-human reservoirs of Ross River virus: A systematic review of the evidence. Parasite. Vector. 11, 188 (2018).

21. Skinner, E. B. et al. Associations between Ross River Virus infection in humans and vector-vertebrate community ecology in Brisbane Australia. Vector-borne Zoonot. https://doi.org/10.1089/vbz.2019.2585 (2020).

22. Martin, L. B., Weil, Z. M. \& Nelson, R. J. Seasonal changes in vertebrate immune activity: Mediation by physiological trade-offs. Philos. T. R. Soc. B. 363, 321-339 (2008).

23. Nelson, R. J. \& Demas, G. E. Seasonal changes in immune function. Quart. Rev. Biol. 71, 511-548 (1996).

24. Old, J. M. \& Deane, E. M. Antibodies to the Ross River virus in captive marsupials in urban areas of eastern New South Wales Australia. J. Wildlife Dis. 41, 611-614 (2005).

25. Muhar, A., Dale, P. E., Thalib, L. \& Arito, E. The spatial distribution of Ross River virus infections in Brisbane: Significance of residential location and relationships with vegetation types. Environ. Health Prev. 4, 184-189 (2000).

26. Ryan, P., Alsemgeest, D., Gatton, M. \& Kay, B. Ross River virus disease clusters and spatial relationship with mosquito biting exposure in Redland Shire, southern Queensland Australia. J. Med. Entomol. 43, 1042-1059 (2006).

27. Davies, N. et al. Movement patterns of an arboreal marsupial at the edge of its range: A case study of the koala. Movement Ecol. 1, 8 (2013).

28. Murphy, A. K. et al. Spatial and temporal patterns of Ross River virus in South East Queensland, Australia: Identification of hot spots at the rural-urban interface. Preprint available at Research Square. https://doi.org/10.21203/rs.3.rs-16140/v1 (2020).

29. Potter, A., Johansen, C. A., Fenwick, S., Reid, S. A. \& Lindsay, M. D. The seroprevalence and factors associated with Ross River virus infection in western grey kangaroos (Macropus fuliginosus) in Western Australia. Vector-borne Zoonot. 14, 740-745 (2014).

30. Kay, B. H., Boyd, A. M., Ryan, P. A. \& Hall, R. A. Mosquito feeding patterns and natural infection of vertebrates with Ross River and Barmah Forest viruses in Brisbane Australia. Am. J. Trop. Med. Hyg. 76, 417-423 (2007).

31. Doak, D. F., Marino, P. C. \& Kareiva, P. M. Spatial scale mediates the influence of habitat fragmentation on dispersal success: Implications for conservation. Theor. Popul. Biol. 41, 315-336 (1992).

32. Fahrig, L. Effects of habitat fragmentation on biodiversity. Annu. Rev. Ecol. Evol. S. 34, 487-515 (2003).

33. Di Giulio, M., Holderegger, R. \& Tobias, S. Effects of habitat and landscape fragmentation on humans and biodiversity in densely populated landscapes. J. Environ. Manag. 90, 2959-2968 (2009).

34. Saunders, D. A., Hobbs, R. J. \& Margules, C. R. Biological consequences of ecosystem fragmentation: A review. Conserv. Biol. 5, 18-32 (1991).

35. Allan, B. F., Keesing, F. \& Ostfeld, R. S. Effect of forest fragmentation on Lyme disease risk. Conserv. Biol. 17, 267-272 (2003).

36. Ostfeld, R. S. Biodiversity loss and the rise of zoonotic pathogens. Clin. Microbiol. Infect. 15, 40-43 (2009).

37. Johnson, B. J. et al. The roles of mosquito and bird communities on the prevalence of West Nile virus in urban wetland and residential habitats. Urban Ecosyst. 15, 513-531 (2012).

38. Quigley, B. L., Ong, V. A., Hanger, J. \& Timms, P. Molecular dynamics and mode of transmission of koala retrovirus as it invades and spreads through a wild Queensland koala population. J. Virology 92 (2018).

39. Woodward, W. et al. Koalas on North Stradbroke Island: diet, tree use and reconstructed landscapes. Wildlife Res. 35, 606-611 (2008).

40. De Oliveira, S., Murray, P., De Villiers, D. \& Baxter, G. Ecology and movement of urban koalas adjacent to linear infrastructure in coastal south-east Queensland. Aust. Mammal. 36, 45-54 (2014).

41. Callaghan, J. et al. Ranking and mapping koala habitat quality for conservation planning on the basis of indirect evidence of treespecies use: A case study of Noosa Shire, south-eastern Queensland. Wildlife Res. 38, 89-102 (2011).

42. MBRC. Koala Management Plan: The Mill at Moreton Bay Redevelopment, Moreton Bay Regional Council. www.moretonbay.qld. gov.au/files/assets/public/services/projects/the-mill/the-mill-koala-management-plan.pdf (2016).

43. Hanger, J. et al. Final Technical Report: Moreton Bay Rail Koala Management Program (Department of Transport and Main Roads, Queensland, 2017).

44. Fabijan, J. et al. Prevalence and clinical significance of koala retrovirus in two South Australian koala (Phascolarctos cinereus) populations. J. Med. Microbiol. 68, 1072-1080 (2019).

45. Whisson, D. A., Zylinski, S., Ferrari, A., Yokochi, K. \& Ashman, K. R. Patchy resources and multiple threats: How do koalas navigate an urban landscape?. Landsc. Urban Plan. 201, 103854 (2020).

46. Mitchell, P. in Biology of the Koala (eds AK Lee, KA Handasyde, \& GD Sanson) 171-187 (1990).

47. Jansen, C. C., Zborowski, P., Ritchie, S. A. \& Van Den Hurk, A. F. Efficacy of bird-baited traps placed at different heights for collecting ornithophilic mosquitoes in eastern Queensland Australia. Aust. J. Med. Entomol. 48, 53-59 (2009). 
48. Johnston, E. et al. Mosquito communities with trap height and urban-rural gradient in Adelaide, South Australia: Implications for disease vector surveillance. J. Vect. Ecol. 39, 48-55 (2014).

49. Kay, B., Boreham, P. \& Fanning, I. Host-feeding patterns of Culex annulirostris and other mosquitoes (Diptera: Culicidae) at Charleville, southwestern Queensland Australia. J. Med. Entomol. 22, 529-535 (1985).

50. Johansen, C., Power, S. \& Broom, A. Determination of mosquito (Diptera: Culicidae) bloodmeal sources in Western Australia: Implications for arbovirus transmission. J. Med. Entomol. 46, 1167-1175 (2009).

51. Kay, B., Fanning, I. \& Carley, J. The vector competence of Australian Culex annulirostris with Murray Valley encephalitis and Kunjin viruses. A J. Exp. Biol. Med. 62, 641-650 (1984).

52. Jacups, S. P., Whelan, P. I. \& Currie, B. J. Ross River virus and Barmah Forest virus infections: A review of history, ecology, and predictive models, with implications for tropical northern Australia. Vector-Borne Zoonot. 8, 283-298 (2008).

53. Hassell, J. M., Begon, M., Ward, M. J. \& Fèvre, E. M. Urbanization and disease emergence: dynamics at the wildlife-livestock-human interface. Trends Ecol. Evol. 32, 55-67 (2017).

54. Kelly, T. R. et al. One Health proof of concept: Bringing a transdisciplinary approach to surveillance for zoonotic viruses at the human-wild animal interface. Prev. Vet. Med. 137, 112-118 (2017).

55. Jansen, C. C. et al. Epidemiologic, entomologic, and virologic factors of the 2014-15 Ross River Virus outbreak, Queensland Australia. Emerg. Infect. Dis. 25, 2243 (2019).

56. Woodruff, R. E. et al. Predicting Ross River virus epidemics from regional weather data. Epidemiology 1, 384-393 (2002).

57. Kelly-Hope, L. A., Purdie, D. M. \& Kay, B. H. Ross River virus disease in Australia, 1886-1998, with analysis of risk factors associated with outbreaks. J. Med. Entomol. 41, 133-150 (2004).

58. Flies, E. J., Flies, A. S., Fricker, S. R., Weinstein, P. \& Williams, C. R. Regional comparison of mosquito bloodmeals in South Australia: Implications for Ross River virus ecology. J. Med. Entomol. 53, 902-910 (2016).

59. Stephenson, E. B., Murphy, A. K., Jansen, C. C., Peel, A. J. \& McCallum, H. Interpreting mosquito feeding patterns in Australia through an ecological lens: An analysis of blood meal studies. Parasite. Vector. 12, 156 (2019).

60. Gordon, G. Estimation of the age of the Koala, Phascolarctos cinereus (Marsupialia: Phascolarctidae), from tooth wear and growth. Aust. Mammal. 14, 5-12 (1991).

61. Robbins, A., Loader, J., Timms, P. \& Hanger, J. Optimising the short and long-term clinical outcomes for koalas (Phascolarctos cinereus) during treatment for chlamydial infection and disease. PLoS ONE 13(12), e0209673. https://doi.org/10.1371/journ al.pone.0209679 (2018).

62. Calenge, C. Home range estimation in R: the adehabitatHR package (Saint Benoist, Auffargis, France, Office national de la classe et de la faune sauvage, 2011).

63. Quantum, G. QGIS geographic information system. Open source geospatial foundation project. https://qgis.osgeo.org (2015).

64. Doherty, R., Whitehead, R. \& Gorman, B. The isolation of a third group A arbovirus in Australia, with preliminary observations on its relationship to epidemic polyarthritis. Aust. J. Sci. 26, 183-184 (1963).

65. Gyawali, N., Taylor-Robinson, A. W., Bradbury, R. S., Potter, A. \& Aaskov, J. G. Infection of Western Gray Kangaroos (Macropus fuliginosus) with Australian arboviruses associated with human infection. Vector-Born Zoonotic Dis. 20, 33-39 (2020).

66. Togami, E. et al. First evidence of concurrent enzootic and endemic transmission of Ross River virus in the absence of marsupial reservoirs in Fiji. Int. J. Infect. Dis. 96, 94-96 (2020).

67. Gyawali, N., Murphy, A. K., Hugo, L. E. \& Devine, G. J. A micro-PRNT for the detection of Ross River virus antibodies in mosquito blood meals: A useful tool for inferring transmission pathways. PLoS ONE 15, e0229314. https://doi.org/10.1371/journ al.pone.0229314 (2020).

68. Gatton, M. L., Kay, B. H. \& Ryan, P. A. Environmental predictors of Ross River virus disease outbreaks in Queensland Australia. Am. J. Trop. Med. Hyg. 72, 792-799 (2005).

69. McGrath, J. C., Drummond, G. B., McLachlan, E. M., Kilkenny, C. \& Wainwright, C. L. Guidelines for reporting experiments involving animals: the ARRIVE guidelines. Br. J. Pharmacol. 160(7), 1573-1576 (2010).

70. QDES. Queensland Department of Environment and Science, Wetland data - version 5 - Queensland series. https://www.des.qld. gov.au (2015).

71. QDES. Queensland Department of Environment and Science, Matters of state environmental significance—wildlife habitat—koala habitat areas-core. https://www.des.qld.gov.au (2020).

72. ESRI. Environmental Systems Research Institute. ArcGIS Desktop. Release 10.4 ed. Redlands, CA, USA. https://esri.com (2020).

\section{Acknowledgements}

This project was significantly supported by the Queensland Government (Department of Transport and Main Roads), and specifically the Moreton Bay Rail project. We thank Moreton Bay Regional Council for initial liaison with the Moreton Bay Rail project and Endeavour Veterinary Ecology. We thank Dr Jonathan Darbro for assisting with sample collection.

\section{Author contributions}

A.R., J.L., J.H. and G.J.D. devised the project. A.R., J.L. and J.H. coordinated field activities. N.G. and O.O. analysed koala sera collections. B.J.J. collated and analysed the data, drafted the manuscript and designed the figures. A.R., A.M., and G.J.D. contributed to the writing of the manuscript. All authors discussed the results and commented on the manuscript.

\section{Competing interests}

AR and JH are employed by Endeavour Veterinary Ecology Pty Ltd. JH was involved in the development of the $K$-Tracker biotelemetry system used during the koala management program. All other authors report no competing interests.

\section{Additional information}

Supplementary Information The online version contains supplementary material available at https://doi. org/10.1038/s41598-021-83919-1.

Correspondence and requests for materials should be addressed to B.J.J.

Reprints and permissions information is available at www.nature.com/reprints.

Publisher's note Springer Nature remains neutral with regard to jurisdictional claims in published maps and institutional affiliations. 
(c) (i) Open Access This article is licensed under a Creative Commons Attribution 4.0 International cc) License, which permits use, sharing, adaptation, distribution and reproduction in any medium or format, as long as you give appropriate credit to the original author(s) and the source, provide a link to the Creative Commons licence, and indicate if changes were made. The images or other third party material in this article are included in the article's Creative Commons licence, unless indicated otherwise in a credit line to the material. If material is not included in the article's Creative Commons licence and your intended use is not permitted by statutory regulation or exceeds the permitted use, you will need to obtain permission directly from the copyright holder. To view a copy of this licence, visit http://creativecommons.org/licenses/by/4.0/.

(C) The Author(s) 2021 